\title{
Fracture criterion and crack stability in grooved beam-like testpieces
}

\author{
Y. W. MAI* \\ Department of Mechanical Engineering, University of Michigan, Ann Arbor, Michigan 48104, U.S.A.
}

(Received April 18, 1975; in revised form October 10, 1975)

\begin{abstract}
In this paper, the fracture criterion for rectangular grooved beam-like testpieces under several loading conditions has been analysed using a simple beam-on-elastic foundation model. Experiments have shown that the model is adequate for describing quasi-static fracture in such test geometries. In addition, the crack stability conditions under both load-controlled and displacement-controlled testing machines are presented.
\end{abstract}

\section{List of symbols}

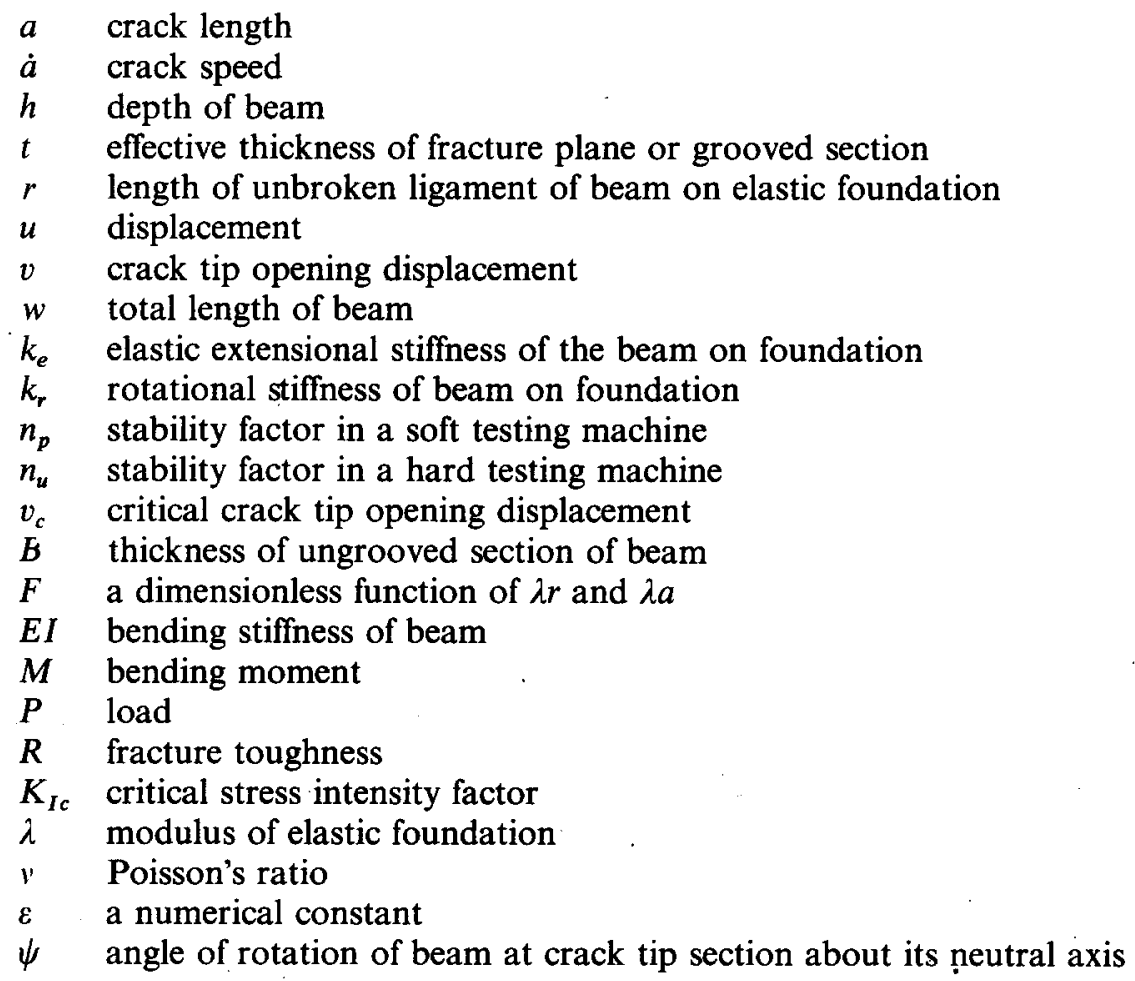

\section{Introduction}

When straight crack paths are desired in beam-like testpieces, it is common practice to introduce face-grooves to control the crack propagation direction. Since there are no readily available stress intensity factor expressions for grooved specimens, there has been some concern about the suitability of using them for fracture toughness testing [1]. * Present address: Dept. of Mechanical Engineering, Imperial College of Science and Technology, London, U.K. 
Moreover, the stability conditions governing spreading cracks in these testpieces have not been previously studied.

Based on a simple beam-on-elastic foundation model, Gurney, Mai and Owen [2] have derived a simple fracture criterion for quasi-static cracking when researching on fracture stability problems. Independently, Kanninen $[3,4]$ has performed extensive investigations on similar problems and come up with similar conclusions. In general, it may be shown that for cracking to occur,

$$
R t=k_{e} v^{2}+k_{r} \psi^{2}
$$

where $R$ is the fracture toughness of material; $t$, effective thickness of fracture plane; $k_{e}$ and $k_{r}$, extension and rotation stiffness of the beam on the elastic foundation; $v$, crack tip opening displacement and $\psi$, the angle of rotation of beam about its neutral axis. Note that in (1), the displacement and rotation at the crack tip section do not both take on unique critical values. It is the sum $\left(k_{e} v^{2}+k_{r} \psi^{2}\right)$ that becomes critical during crack propagation.

Equation (1) has been successfully applied to double cantilever beam specimens under wedge-loading [3, 4]. It is anticipated that the equation can also be extended to other beam-like specimen geometries and under some other loading conditions. In particular, it should be useful for predicting fracture in those specimens with grooves on their faces.

When discussion is confined to quasi-static crack propagation processes ${ }^{\star}$, Kanninen [4] has shown that the fracture criterion is appropriately reduced to

$$
R t=k_{e} v_{c}^{2}
$$

where $v_{c}$ is the critical crack tip opening displacement. This argument is supported by results shown in Fig. 2 of Kanninen's paper [4].

The deflections of semi-infinite and finite beams on elastic foundations under a range of loading conditions are given in Hetenyi [5]. Thus, substituting these crack tip displacement (v) expressions in (2) and simplifying, we obtain an equivalent fracture criterion as

$$
M /(R E I t)^{\frac{1}{2}}=F(\lambda r, \lambda a),
$$

where $M$ is the bending moment at the crack tip to cause quasi-static crack extension, and $F$ is a function of $\lambda r$ and $\lambda a ; a$ is the crack length, $\dot{r}$ the unbroken ligament of the beam on the elastic foundation and $\left.\lambda=\left[k_{e} / 4 E I\right)\right]^{\frac{1}{1}}$. When the cracked testpiece is reversible and elastic, so that $K_{I c}^{2}=E R /\left(1-v^{2}\right)$, the critical stress intensity factor $\left(K_{I c}\right)$ can be expressed in terms of $F(\lambda r, \lambda a)$ and $M$, without going through complicated stress analysis at the crack tip. However, it should be pointed out that $K_{I c}$ estimates using the beam-on-elastic foundation analysis still involve the experimental determination of the spring stiffness $\left(k_{e}\right)$ and knowledge of the crack tip opening displacement $(v)$.

The stability conditions governing a spreading crack, under the constraints of either a load $(P)$ or a displacement $(u)$ controlled machine, have been discussed extensively in $[2,6-11]$. In terms of the relative displacement at the crack tip section $(v)$, these stability conditions can be re-written as follows:

(1) For a load-controlled machine (i.e. $\mathrm{d} P / P>0$ ),

\footnotetext{
$\star$ "Quasi-static" is used in the sense that negligible generation of kinetic energy occurs during crack propagation. For more details, see [6] and [7].
} 


$$
\frac{1}{R} \frac{\mathrm{d} R}{\mathrm{~d} a}>\frac{2}{v}\left(\frac{\partial v}{\partial a}\right)_{p}=\frac{n_{p}}{a}
$$

(2) For a displacement-controlled machine (i.e. $\mathrm{d} u / u>0$ ),

$$
\frac{1}{R} \frac{\mathrm{d} R}{\mathrm{~d} a}>\frac{2}{v}\left[\left(\frac{\partial v}{\partial a}\right)_{p}-\frac{v^{3}}{\int_{0}^{a} v^{2} \mathrm{~d} a}\right]=\frac{n_{u}}{a} .
$$

The right-hand side terms of expressions (4) and (5) (i.e. $n_{p} / a$ and $n_{u} / a$ ), are known as the geometrical stability factors (g.s.f.) for a load- and a displacement-controlled machine respectively $[2,7]$. The smaller their algebraic magnitude, the better the stability of cracking (i.e. large negative values promote crack stability). In general, it is seen that negative $\mathrm{d} R / \mathrm{d} \dot{a}$ makes stable cracking difficult (i.e. when $R$ decreases with increasing crack speed) unless the g.s.f. are very negative. It should be pointed out that the stability conditions given in (4) and (5) are essentially the same as those derived independently by Clausing [10] (see for example, (24) and (25) in [10]. This fact has also been discussed by Atkins and Caddell [12]. Thus, the stability factors $n_{p}$ and $n_{u}$ in the present paper are equivalent to $f_{2}(a / w)$ and $\left(f_{2}-f_{3}\right)(a / w)$ respectively as given in Clausing's paper.

In the present investigation, we have analysed and examined the quasi-static fracture criterion according to (3) for a few grooved beam-like test-pieces under a range of loading conditions. Both experimental and theoretical results will be compared. In addition, crack stability conditions for these examples, under both load-controlled and displacement-controlled constraints, are also presented.

\section{Quasi-static fracture criterion and stability conditions}

In this section, fracture criterion and crack stability conditions are investigated for beam-like testpieces with grooves on their faces using the simple beam-on-elastic foundation model.

\subsection{Double-ended cantilever beam under central cracking}

Consider a finite double-ended cantilever beam (with $\lambda r<\pi$ ) under central cracking in the longitudinal direction as shown in the inset of Fig. 1. From Hetenyi [5], it may be shown that the crack tip opening displacement is given by,

$$
\begin{aligned}
v_{A}= & v_{B}=\frac{P \lambda}{4 k_{e}}\left\{\frac{\lambda^{2} a^{2}\left(\operatorname{Sinh}^{2}(\lambda r)-\sin ^{2}(\lambda r)\right)-4\left(\operatorname{Sinh}^{2}(\lambda r)+\sin ^{2}(\lambda r)\right)}{\left[\lambda a\left(\operatorname{Sinh}^{2}(\lambda r)-\sin ^{2}(\lambda r)\right)+\operatorname{Sinh}(2 \lambda r)+\sin (2 \lambda r)\right]}\right. \\
& \left.\times \frac{\left(\operatorname{Sinh}^{2}(\lambda r)+\sin ^{2}(\lambda r)\right)}{\left(\operatorname{Sinh}^{2}(\lambda r)-\sin ^{2}(\lambda r)\right)}+4\left(\frac{\operatorname{Sinh}(\lambda r) \operatorname{Cosh}(\lambda r)-\sin (\lambda r) \cos (\lambda r)}{\operatorname{Sinh}^{2}(\lambda r)-\sin ^{2}(\lambda r)}\right)\right\} .
\end{aligned}
$$

For quasi-static crack extension to commence,

$$
v_{A}=v_{B}=\left(R t / k_{e}\right)^{\frac{1}{2}},
$$

so that

$$
M /(R E I t)^{\frac{1}{2}}=\lambda^{2} a P / 4 k_{e} v_{A} .
$$

The conditions governing crack stability (see (4) and (5)) are very complicated 


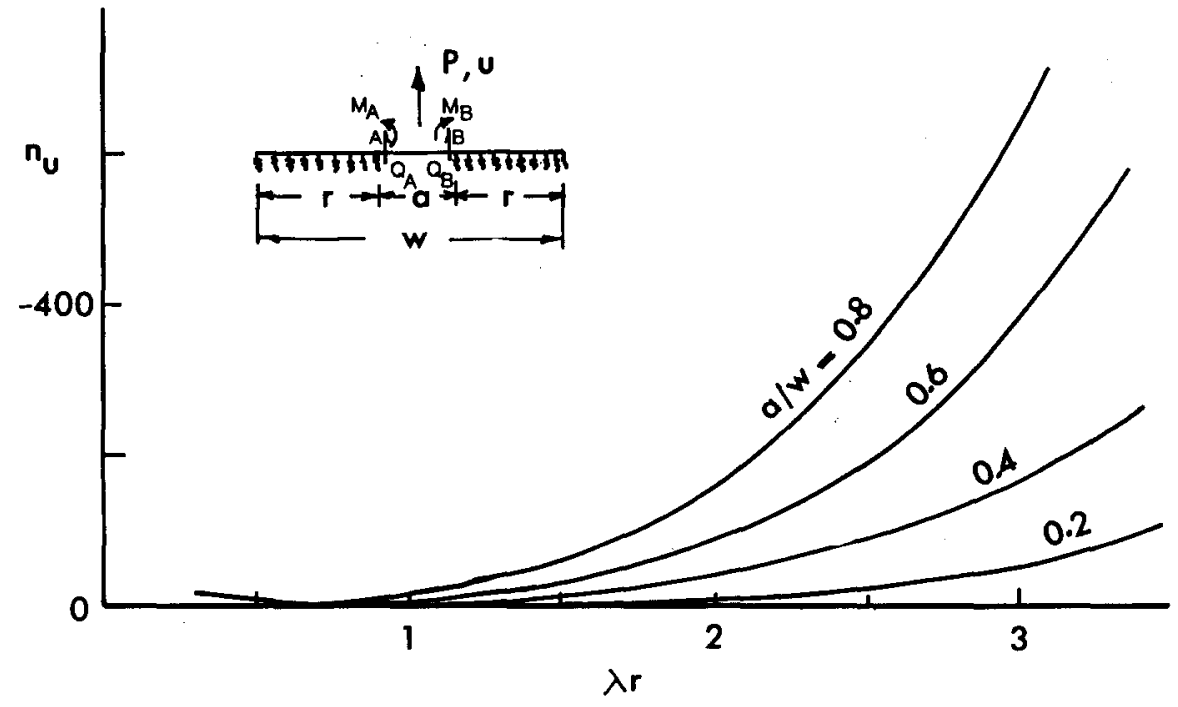

Figure 1(a). Relations between $n_{u}$ and $\lambda r$ for a finite beam under central cracking, $(\lambda r<\pi)$.

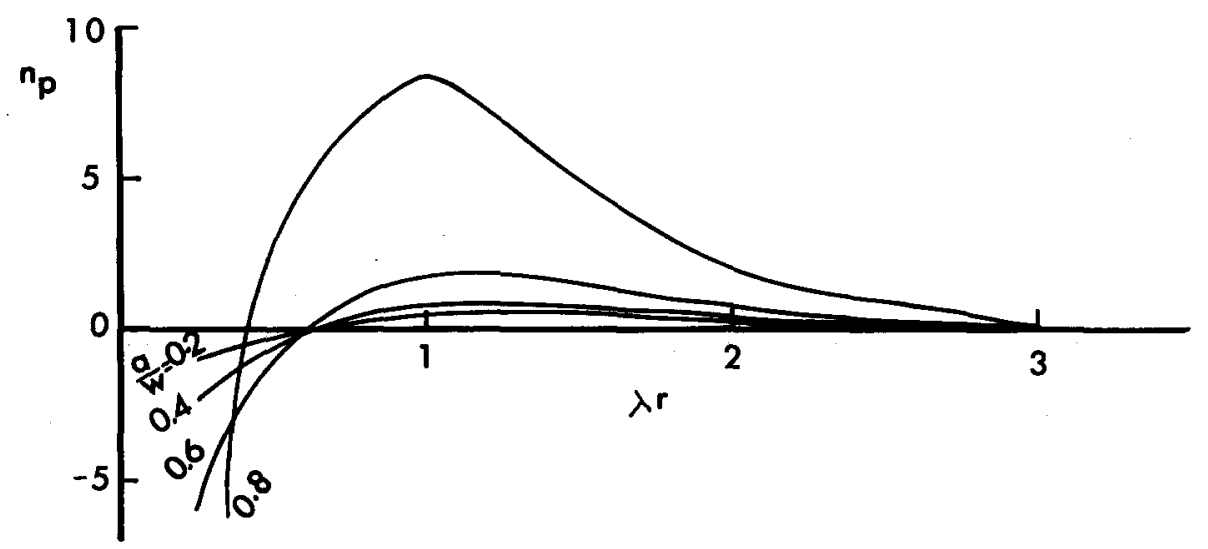

Figure 1(b). Relations between $n_{p}$ and $\lambda r$ for a finite beam under central cracking $(\lambda r<\pi)$.

mathematical expressions. For simplicity, $n_{u}$ and $n_{p}$ have been plotted against $\lambda r(<\pi)$, for varying $a / w$ in Figs. 1(a) and 1(b). To have better ideas of these stability factors during continuous quasi-static crack extension, let us consider the case of a hard testing machine when two grooved testpieces with same $w(=250 \mathrm{~mm})$ but different $\lambda$ values (assuming $2 \times 10^{-2}$ and $4 \times 10^{-2} \mathrm{~mm}^{-1}$ respectively) are cracked by a central force as illustrated in the inset of Fig. 2. $n_{u}$ is seen to decrease for both specimens with increasing $\lambda a$ or decreasing $\lambda r$, but comparatively, stability is shown to be better for the specimen with a bigger $\lambda$ value (see Fig. 2). Note that for specimens with the same groove dimensions, $\lambda$ can be increased by reducing the depth of the arms $(h)$.Thus, this implies that more slender beams will provide better stability of cracking, a conclusion which is also reached in Mai, Atkins and Caddell [13].

When the beam shown in Fig. 1 is such that $\lambda r>\pi$, (6) yields an approximate solution for the crack tip displacements at $A$ and $B$ as,

$$
v_{A}=v_{B}=\frac{P \lambda}{4 k_{e}}(2+\lambda a) .
$$



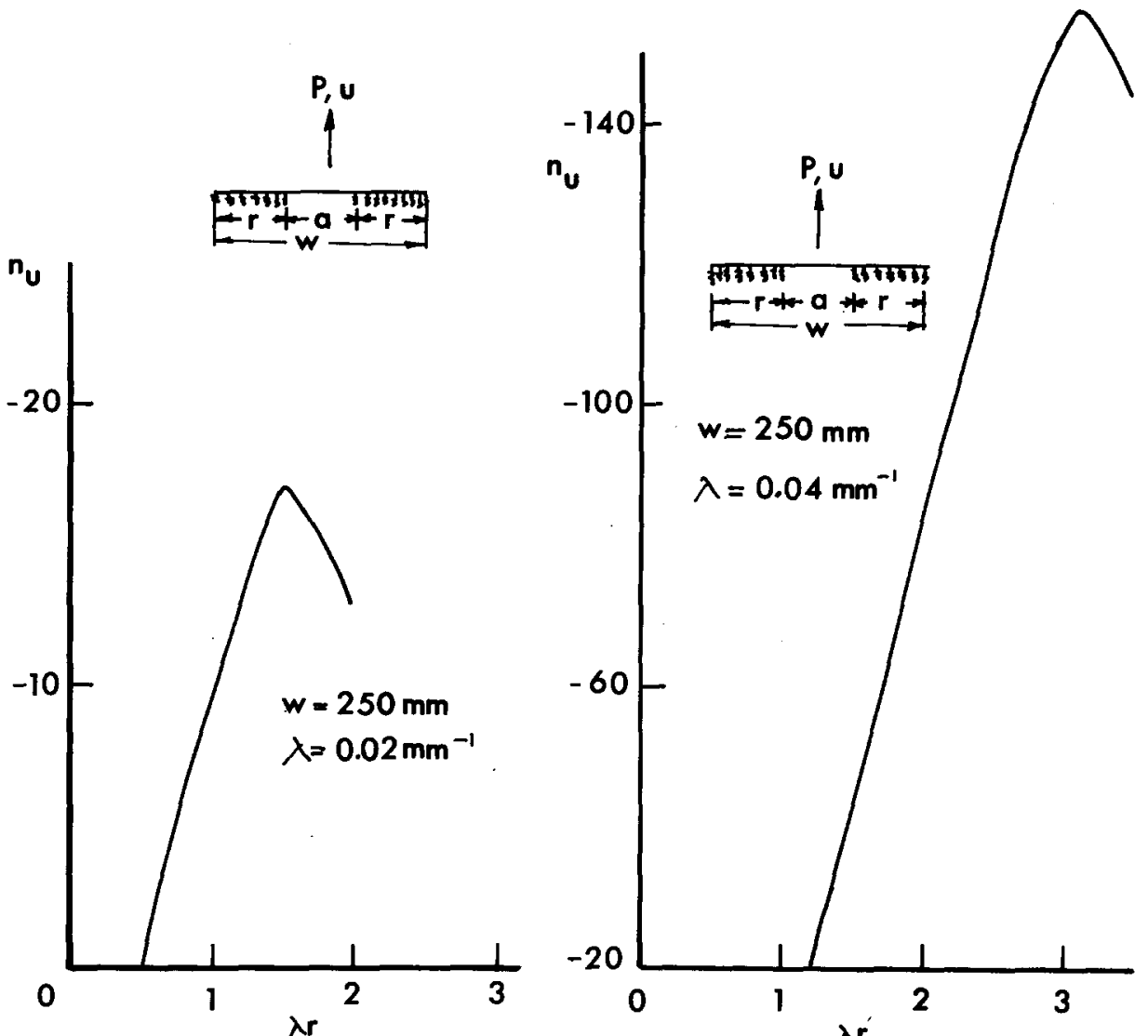

Figure 2. Variation of stability factor $n_{u}$ during progressive cracking for two similar specimens with different $\lambda$ values.

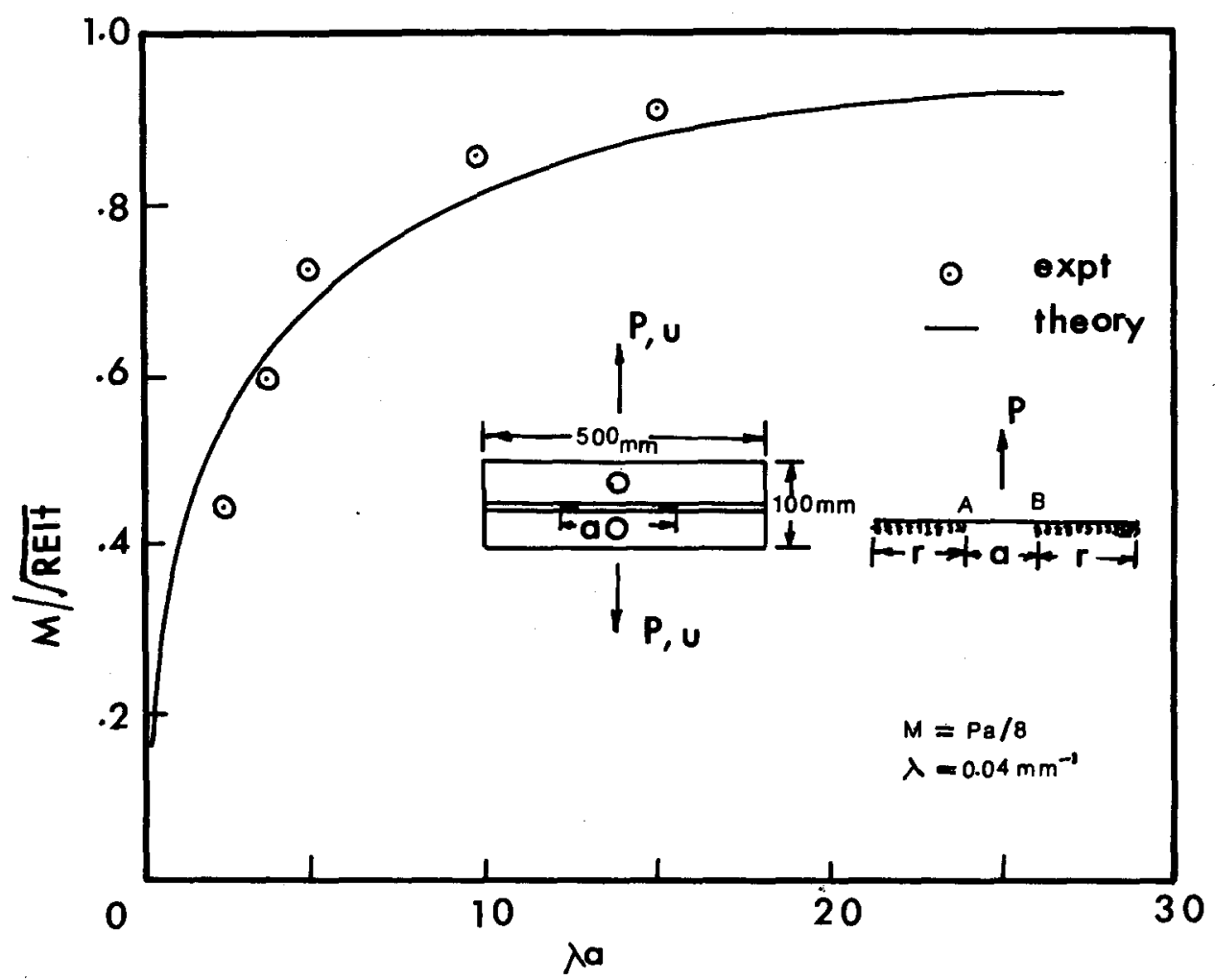

Figure 3. Variation of $M /(R E I t)^{\frac{1}{2}}$ with $\lambda a$ for a finite beam under central cracking, $(\lambda r>\pi)$. 

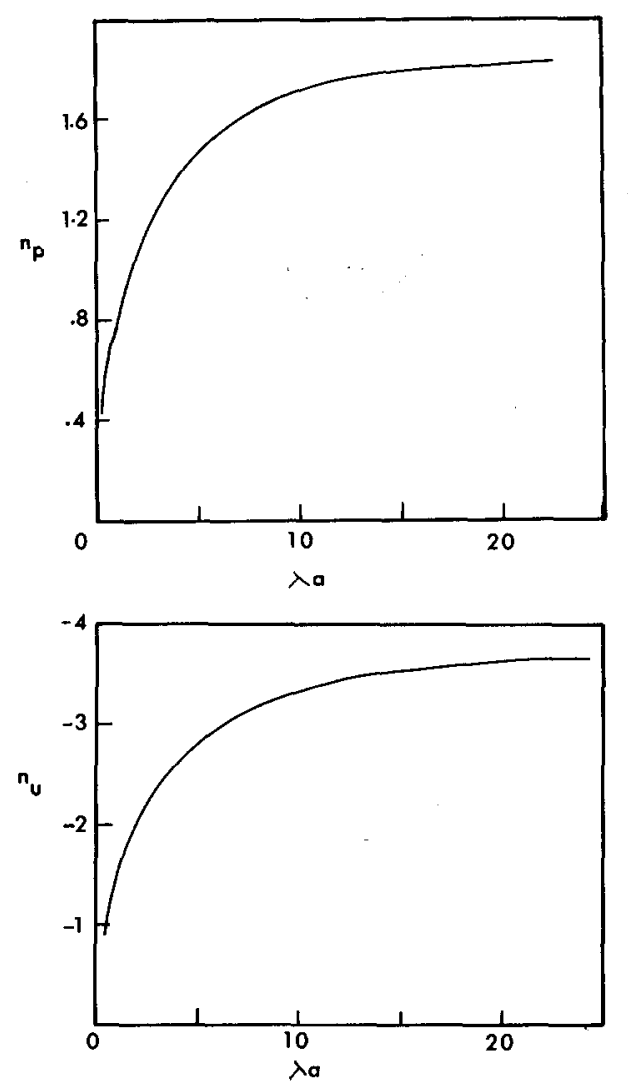

Figures 4(a) and (b). Variations of $n_{p}$ and $n_{u}$ with $\lambda a$ for a finite beam under central cracking $(\lambda r>\pi)$.

Thus, substitution of (8) into (2), we obtain,

$$
M /(R E I t)^{\frac{1}{2}}=F(\lambda a)=\lambda a /(2+\lambda a),
$$

where $M=P a / 8$, which is the bending moment (according to beam theory) applied at the crack tips $A$ and $B$.

Figure 3 shows a plot of theoretical $M /(R E I t)^{\frac{1}{2}}$ versus $\lambda a$. It is clear that $M^{2}=R E I t$ only holds when $\lambda a \rightarrow \infty$. Crack propagation experiments were also conducted with a view to see how accurate experimental data were when compared with theoretical $M /(R E I t)^{\frac{1}{2}}$ values. $6 \mathrm{~mm}$ thick Perspex specimens with rectangular dimensions 500 $\mathrm{mm} \times 100 \mathrm{~mm}$ were used. Face grooves with $1.53 \mathrm{~mm}$ depth and $6 \mathrm{~mm}$ width were made on the two faces of the testpiece as shown in the inset of Fig. 3. For accuracy, the value of $k_{e}$ was determined experimentally instead of using derived equations similar to that given by Kanninen $[3,4]$. The procedures of $k_{e}$ determination have been given in $[2,19]$. Briefly, this involved loading in tension tensile specimens ${ }^{\star}$ of different widths made from the grooved testpiece and plotting the measured stiffness against the specimen width. $k_{e}$ was given by twice the measured slope of this plot. The foundation modulus $(\lambda)$ could then be calculated from $\left(k_{e} / 4 E I\right)^{\frac{1}{2}}$, where all physical quantities were now known. In this way, we found that $\lambda$ was approximately $0.04 \mathrm{~mm}^{-1}$ for the present grooved testpiece. For the purpose of plotting the experimental results, $R$ for Perspex was

* Note that all these tensile specimens have reduced sections corresponding to the face grooves midway along their lengths. 
determined from the well-known irreversible work area method of Gurney and co-workers $[2,6-8,13,14,19]$. Thus, during the quasi-static crack propagation experiments, given crack lengths $(a)$ and corresponding fracture loads $(P)$, the experimeptal values of $M /(R E I t)^{\frac{1}{2}}$ could be estimated and compared with theoretical solutions given by (9). These experimental data were superimposed on Fig. 3, and agreement with theoretical values was good.

The stability condition of a spreading crack under the constraints of a load-controlled machine (i.e. $\mathrm{d} P / P>0$ ) is given by (4), where

$$
\frac{1}{R} \frac{\mathrm{d} R}{\mathrm{~d} a}>\frac{2}{a}\left(\frac{\lambda a}{2+\lambda a}\right)=\frac{n_{p}}{a}
$$

so that $n_{p}=2 \lambda a /(2+\lambda a)$. For a displacement-controlled machine, (i.e. du/u>0), from (5), the stability condition becomes,

$$
\frac{1}{R} \frac{\mathrm{d} R}{\mathrm{~d} a}>2\left[\frac{\lambda}{2+\lambda a}-\frac{v^{2}}{\int_{0}^{a} v^{2} \mathrm{~d} a}\right]>-\frac{4}{a}\left(\frac{\lambda a}{2+\lambda a}\right)=\frac{n_{u}}{a},
$$

where $n_{u}=-4 \lambda a /(2+\lambda a)$.

Figures 4(a) and (b) show the variation of $n_{p}$ and $n_{u}$ with $\lambda a$. In general, stability is shown not only to be better in a displacement-controlled machine, but also improves as $\lambda a$ increases (i.e. as the crack proceeds).

\subsection{Crack-line loaded edge-crack specimen}

The inset of Fig. 5(a) shows a crack-line loaded edge-crack or straight doublecantilever beam specimen. The crack tip displacement at $A$ is given by [5]

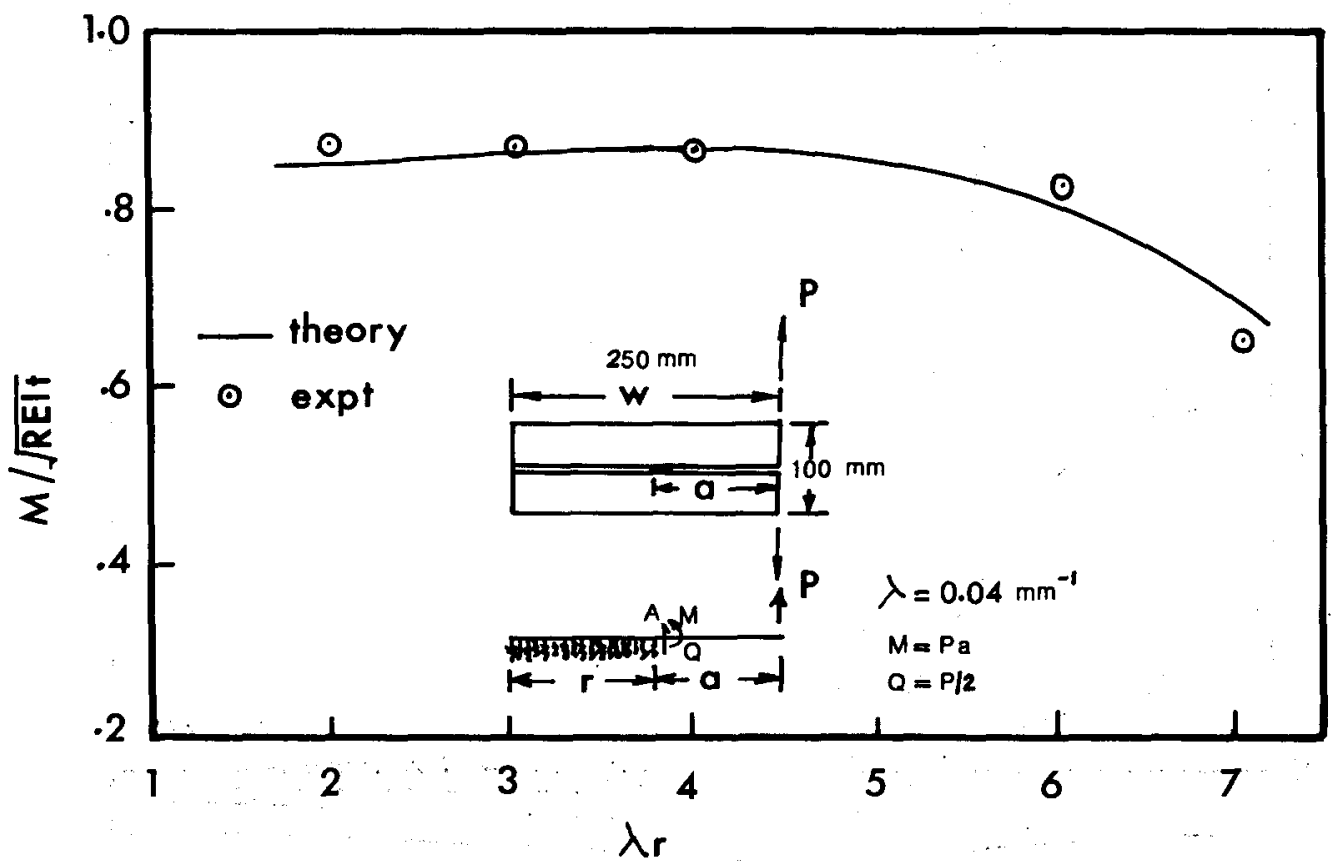

Figure 5(a). Comparison of theoretical and experimental $M /(R E I t)^{\frac{1}{2}}$ for varying $\lambda r$ in a grooved DCB specimen. 


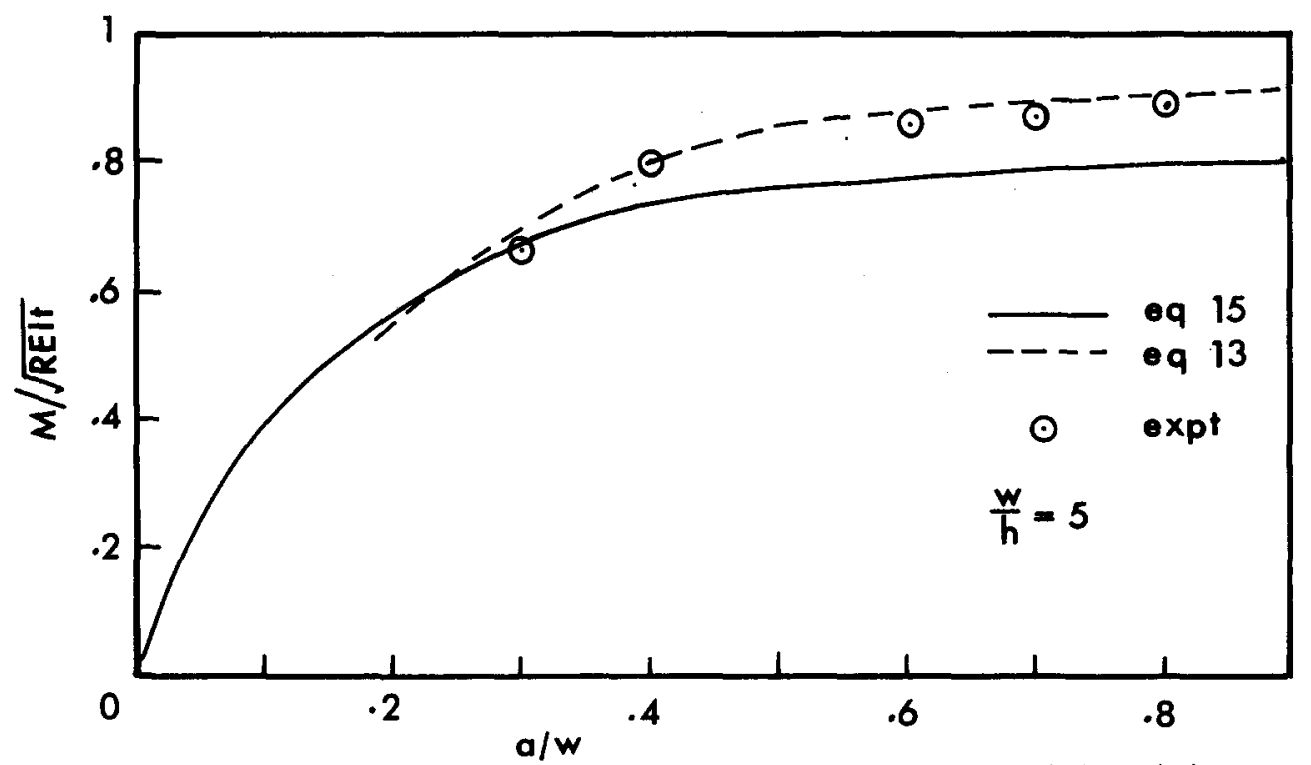

Figure 5(b). Comparison of experimental $M /(R E I t)^{\frac{1}{2}}$ for varying $a / w$ with equations (13) and (15).

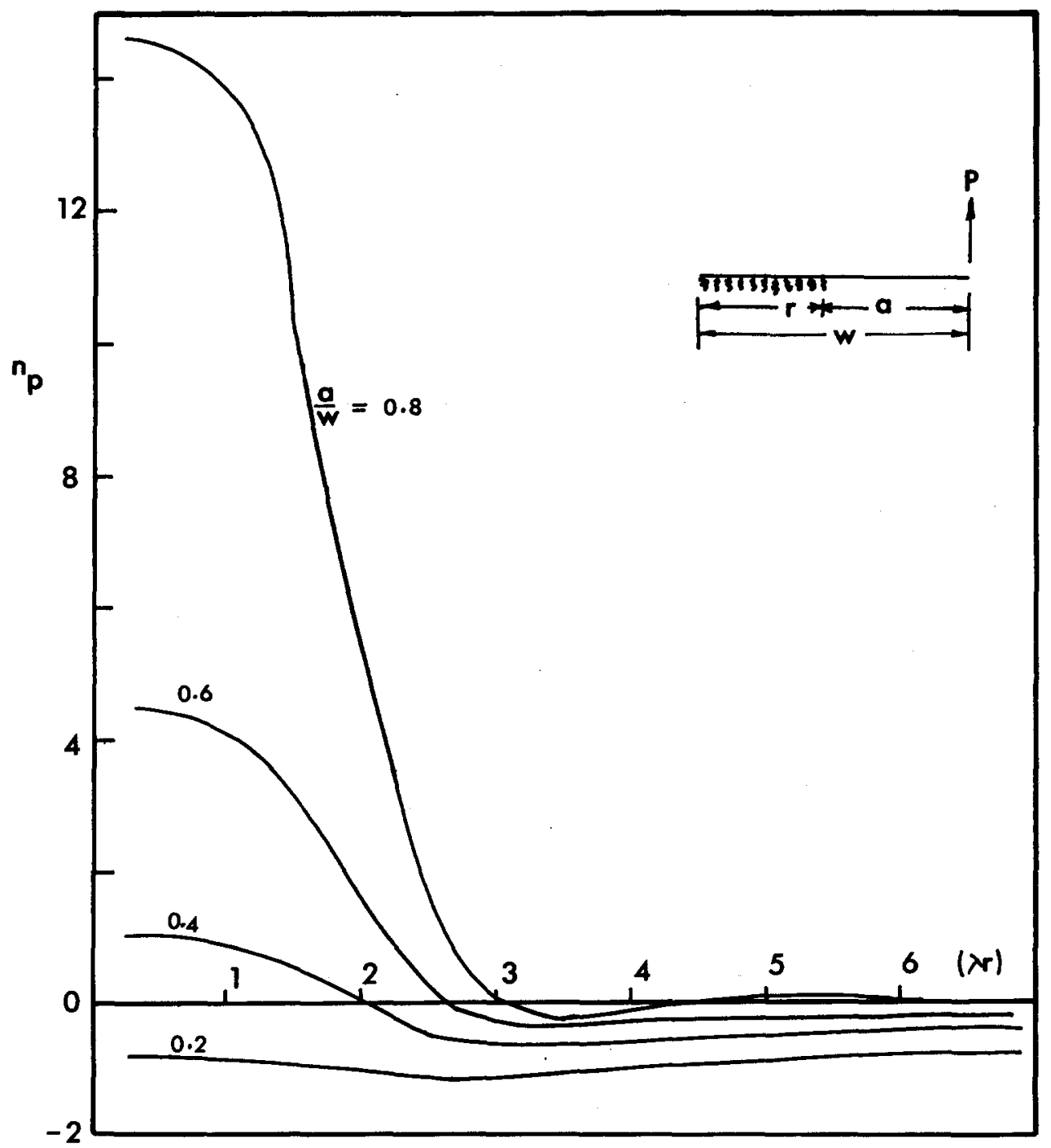

Figure 6(a). Variation of stability factors $n_{p}$ and $n_{\psi}$ with $\lambda r$ in a grooved DCB specimen. 


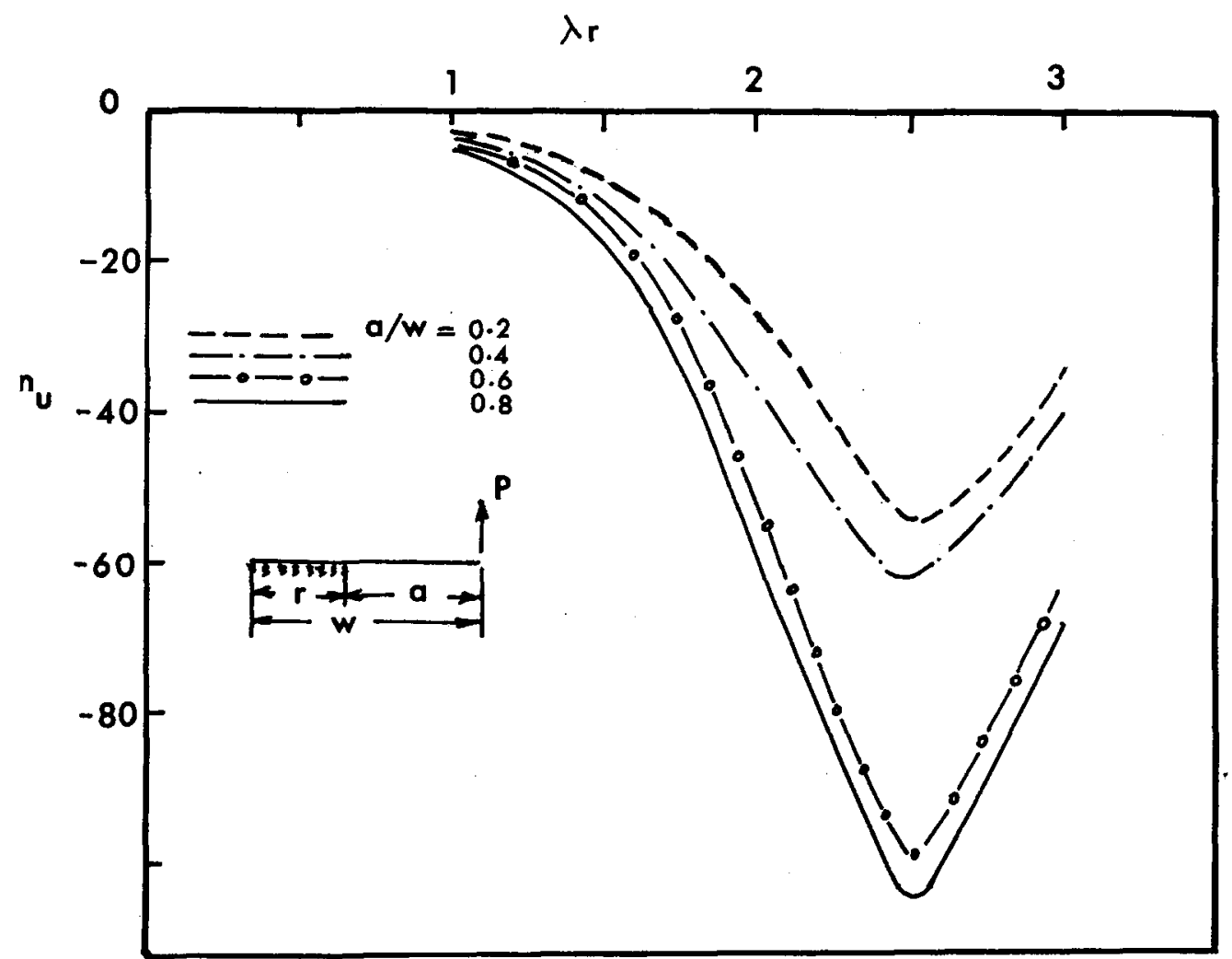

Figure $6(\mathrm{~b})$.Variation of stability factors $n_{p}$ and $n_{u}$ with $\lambda r$ in a grooved DCB specimen.
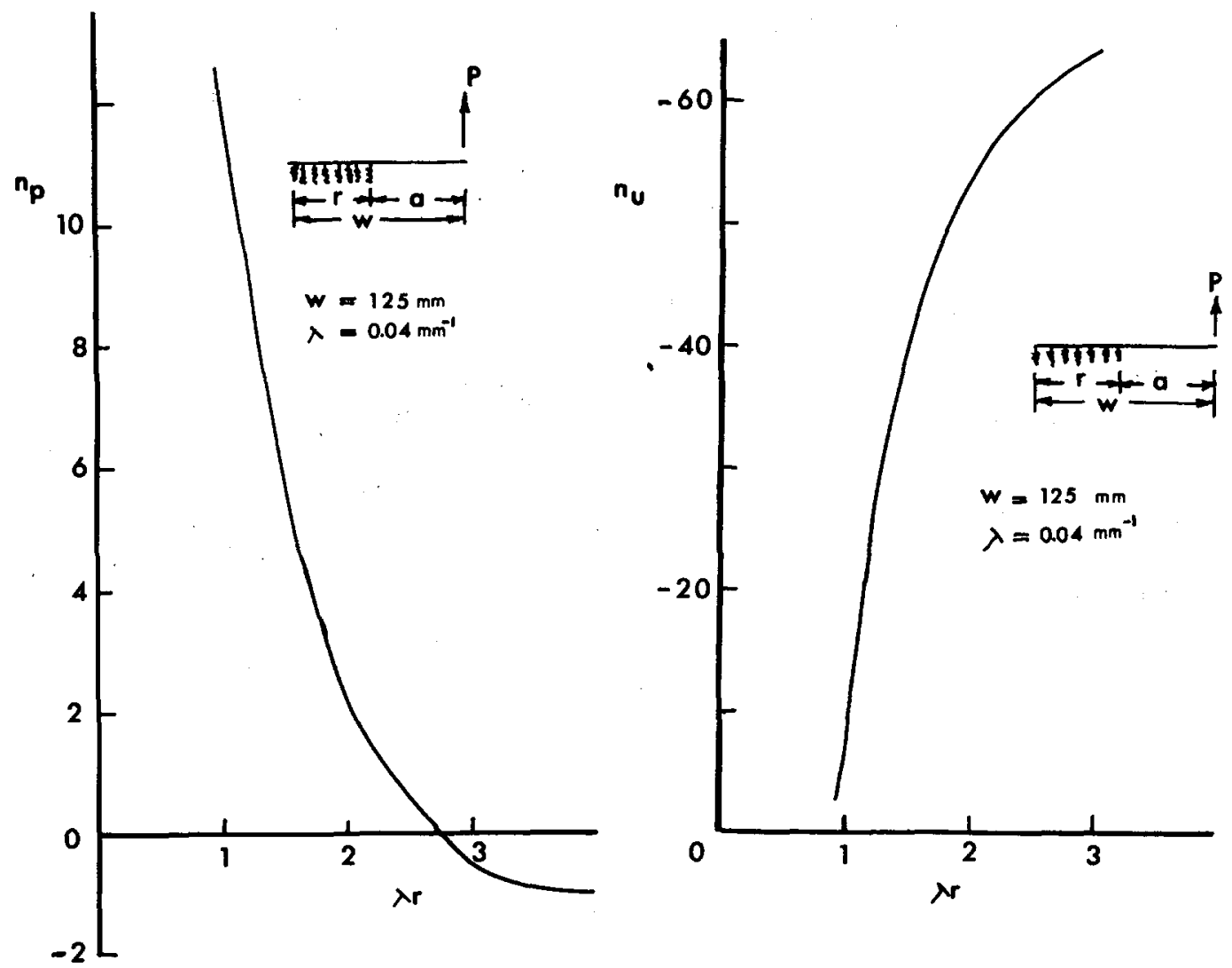

Figure $6(\mathrm{c})$. Stability factors $n_{p}$ and $n_{u}$ for a DCB grooved specimen during progressive cracking. 


$$
v_{A}=\frac{2 P a}{k_{e}} \lambda^{2}\left[\frac{\operatorname{Sinh}^{2}(\lambda r)+\sin ^{2}(\lambda r)}{\operatorname{Sinh}^{2}(\lambda r)-\sin ^{2}(\lambda r)}\right]+\frac{2 P \lambda}{k_{e}}\left[\frac{\operatorname{Sinh}(\lambda r) \operatorname{Cosh}(\lambda r)-\sin (\lambda r) \cos (\lambda r)}{\operatorname{Sinh}^{2}(\lambda r)-\sin ^{2}(\lambda r)}\right] .
$$

Manipulations of (2), (3) and (12), give the quasi-static fracture criterion as

$$
\frac{M}{(R E I t)^{\frac{1}{2}}}=\frac{\lambda a\left[\operatorname{Sinh}^{2}(\lambda r)-\sin ^{2}(\lambda r)\right]}{\lambda a\left[\operatorname{Sinh}^{2}(\lambda r)+\sin ^{2}(\lambda r)\right]+\operatorname{Sinh}(\lambda r) \operatorname{Cosh}(\lambda r)-\sin (\lambda r) \cos (\lambda r)}
$$

Figure 5(a) shows the variation of $M /(R E I t)^{\frac{1}{2}}$ with $\lambda r$, according to (13). The finite length $(w)$ of the specimen is taken as $250 \mathrm{~mm}$ in these calculations. It follows that when $\lambda a \rightarrow \infty$ and $\lambda r>\pi, M^{2}=R E I t$. However, it has been found that in some published work (e.g. $[6,15]), M^{2}=R E I t$, has been invariably taken as the fracture criterion for the crack-line loaded edge-crack or straight DCB specimens (whether they are grooved or not). This is not necessarily true because it only holds in the asymptotic case, as is shown here.

Similar experiments as those described in section 2.1. were run on $250 \times 100 \times 6 \mathrm{~mm}$ specimens made from cast sheets of Perspex. The groove dimensions were the same as those used in the previous example. Because the bending stiffness $(E I)$ of the beam on the foundation is constant, it follows that the foundation modulus $(\lambda)$ should have the same value. These experimental results were also plotted in Fig. 5(a).

Johnson and Radon [16] suggest that for a grooved DCB specimen, the critical stress intensity factor $\left(K_{I c}\right)$ can be written as,

$$
K_{I c}=\frac{3.46 P(a / h+0.7)}{\left[t B h\left(1-v^{2}\right)\right]^{\frac{1}{2}}}
$$

where $h$ is the depth of the arm, $v$ the Poisson's ratio, $B$ the thickness of the ungrooved section and $t$ that of the fracture plane. This equation is in fact a modification of the Gross-Srawley boundary collocation solution [17] for an ungrooved specimen. Equation (14) can also be expressed as

$$
\frac{M}{(R E I t)^{\frac{1}{2}}}=\frac{[(a / w) / h / w)]\left(1-v^{2}\right)^{\frac{1}{2}}}{[(a / w) /(h / w)+0.7]}
$$

It is useful to compare the experimental data with the theoretical predictions made from (13) and (15), so that the relative accuracies of the beam-on-elastic foundation analysis and the Johnson-Radon equation can be directly compared.

For the specimen just described, with $w / h=5.0, \lambda=4 \times 10^{-2} \mathrm{~mm}^{-1}$ and $w=250 \mathrm{~mm}$, $M /(R E I t)^{\frac{1}{2}}$ may be plotted against $(a / w)$ as shown in Fig. 5(b). It may be seen that the experimental data are in better agreement with the beam-on-elastic foundation model than with the Johnson-Radon equation.

The stability condition of a spreading crack under the constraint of a load-controlled machine can be found from (4) and (12). Thus,

$$
\begin{aligned}
\frac{1}{R} & \frac{\mathrm{d} R}{\mathrm{~d} a}>\frac{-2}{a}\left\{\operatorname{Sinh}(\lambda r) \operatorname{Cosh}(\lambda r)-\sin (\lambda r) \cos (\lambda r)+\frac{4(\lambda a)^{2} \operatorname{Sinh}(\lambda r) \sin (\lambda r)}{\operatorname{Sinh}^{2}(\lambda r)-\sin ^{2}(\lambda r)}\right. \\
& \times[\operatorname{Sinh}(\lambda r) \cos (\lambda r)-\sin (\lambda r) \operatorname{Cosh}(\lambda r)] \\
& \left.-2 \lambda a\left[\frac{\left.\operatorname{Sinh}^{2}(\lambda r)-2 \sin (\lambda r) \cos (\lambda r) \operatorname{Sinh}(\lambda r) \operatorname{Cosh}(\lambda r)-\sin (\lambda r) \cos (\lambda r)\right]}{\operatorname{Sinh}^{2}(\lambda r)-\sin ^{2}(\lambda r)}\right]\right\} \\
& \div\left\{\lambda a\left(\operatorname{Sinh}^{2}(\lambda r)+\sin ^{2}(\lambda r)\right)+\operatorname{Sinh}(\lambda r) \operatorname{Cosh}(\lambda r)-\sin (\lambda r) \cos (\lambda r)\right\}=n_{p} / a
\end{aligned}
$$


To take into account of the finite length $(w)$ of the beam, it may be noted that $\lambda a=\lambda r /(w / a-1)$. Therefore, $n_{p}$ may be plotted against $\lambda r$ for varying $a / w$. Such curves are shown in Fig. 6(a). In the broadest sense, it may be seen that stable cracking is difficult to achieve under such loading conditions since $n_{p}$ are large positive numbers.

The crack stability criterion in a displacement-controlled machine, as worked out from (5), is cumbersome. The value of $n_{u}$, however, is shown in Fig. 6(b) as a function of $\lambda r$ for varying $a / w$. Obviously, stability is markedly increased when compared with the case of an ungrooved DCB specimen as shown in Gurney and Hunt* [6] in which $n_{u}=-4.0$.

To gain better insight into the crack stability conditions, consider a grooved DCB specimen in which $\lambda=4 \times 10^{-2} \mathrm{~mm}^{-1}$ and $w=125 \mathrm{~mm}$. Figure $6(\mathrm{c})$ shows the variation of $n_{u}$ and $n_{p}$ with $\lambda r$. Note that when the crack extends, $\lambda r$ decreases. In this way, it may be seen that cracking should be very stable in a hard testing machine and unstable in a soft one.

Following this implication that a grooved DCB specimen promotes stable cracking in a hard testing machine, experiments are performed on polycarbonate which is an unstable,

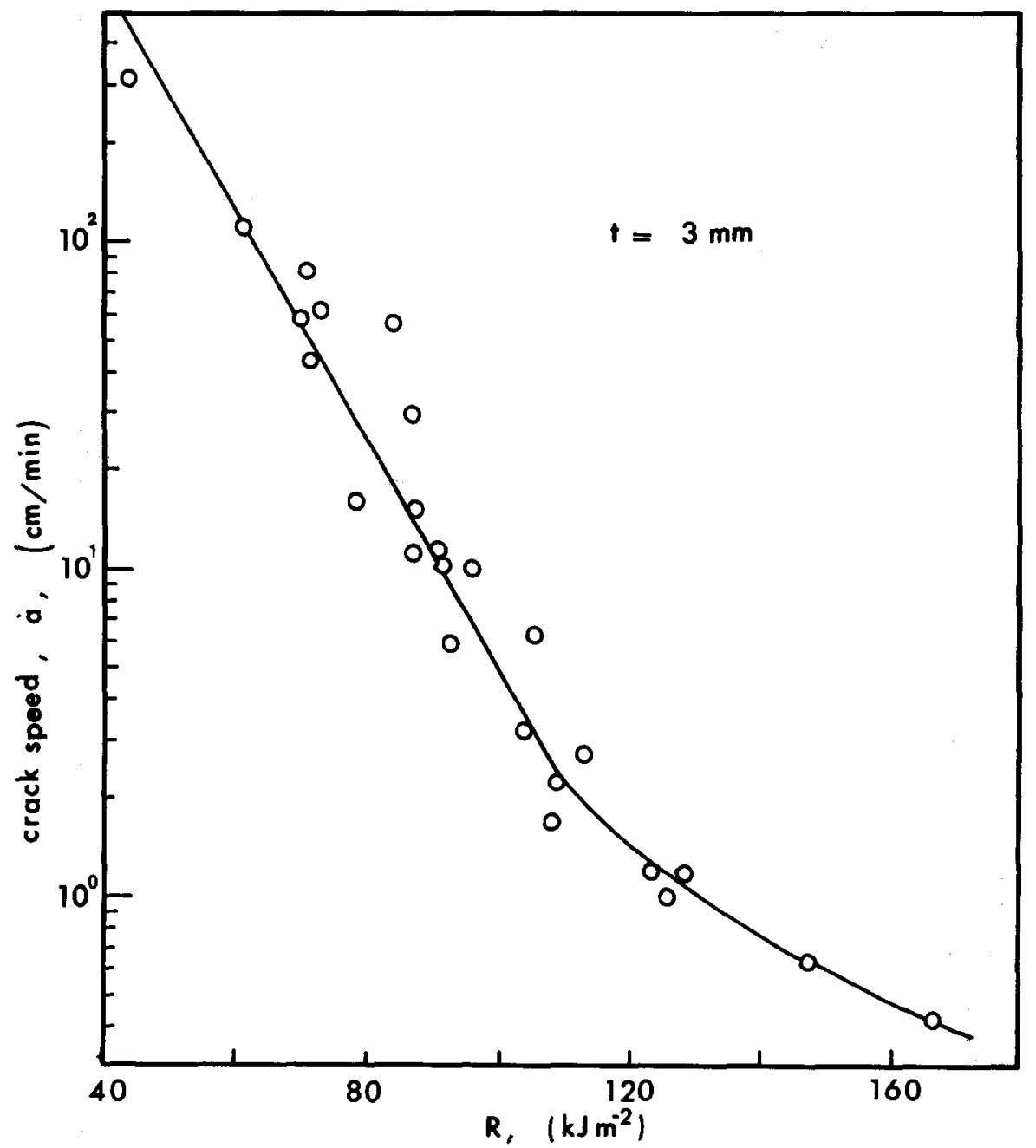

Figure 7. Variation of fracture toughness $(R)$ with crack speed $(\dot{a})$ for polycarbonate.

* It should be noted that the derivation given in Gurney and Hunt [6] is based on a rigid foundation and an Euler-Bernoulli beam and is hence inadequate. 
rate sensitive material with $\mathrm{d} R / \mathrm{d} \dot{a}<0$. Experimental results showed that cracking was indeed stable in these grooved specimens. Therefore, useful $R(\dot{a})$ information could be obtained easily. Figure 7 shows the variation of $R$ with $\dot{a}$ for polycarbonate. Note that cracking in ungrooved specimens of polycarbonate is violently unstable.

2.3. Single-ended double cantilever beam specimens subjected to bending moments at the ends

The inset of Fig. 8 shows a grooved DCB specimen with unequal bending moments $M$

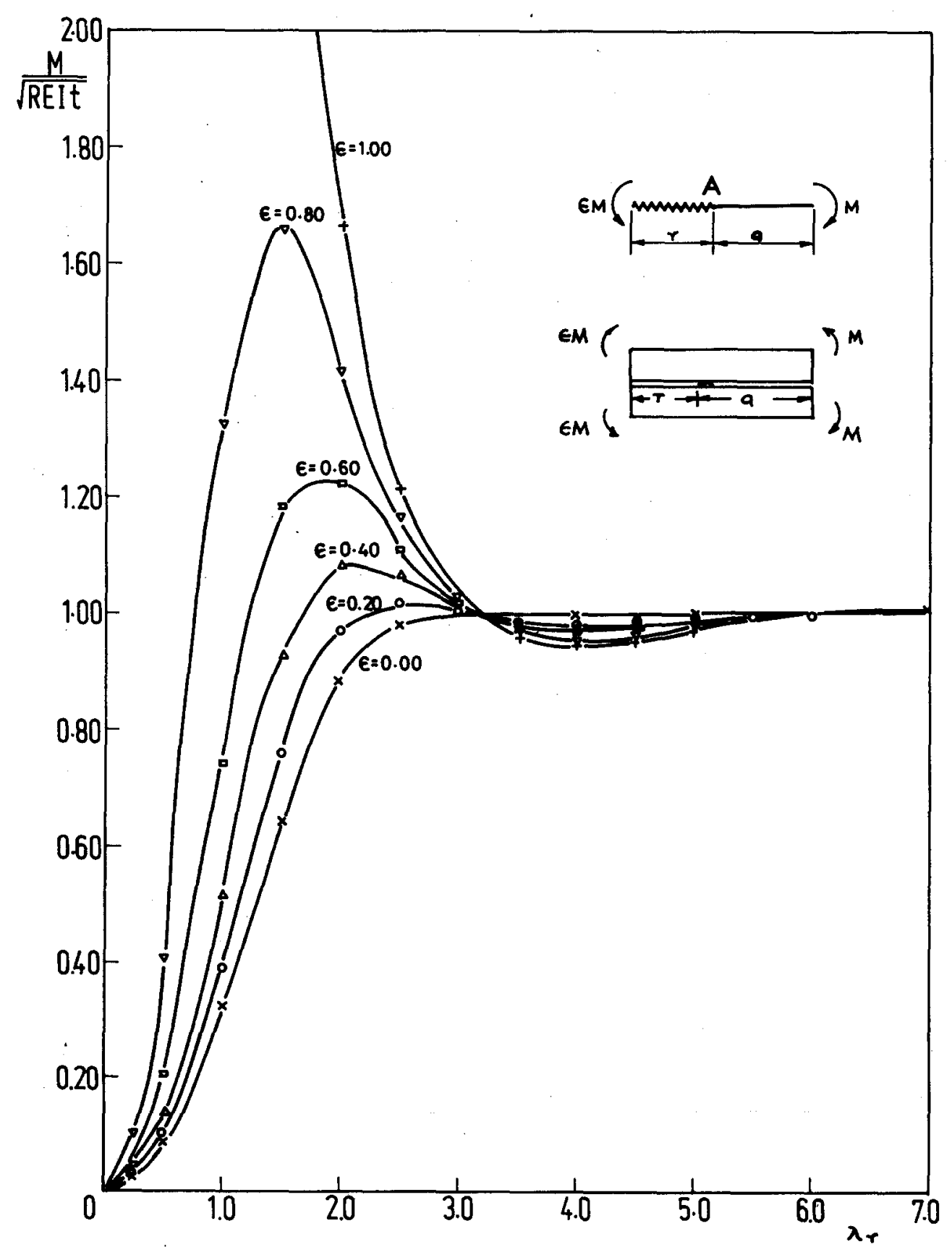

Figure 8. Relations between bending moment to cause propagation of a crack and $\lambda r$ for varying $\varepsilon$. 
and $\varepsilon M$ applied at the ends. The crack tip opening displacement at $A$ is given by

$$
v_{A}=\frac{2 M \lambda^{2}}{k_{e}}\left[\frac{\operatorname{Sinh}^{2}(\lambda r)+\sin ^{2}(\lambda r)}{\operatorname{Sinh}^{2}(\lambda r)-\sin ^{2}(\lambda r)}\right]-\frac{4 \varepsilon M \lambda^{2}}{k_{e}}\left[\frac{\operatorname{Sinh}(\lambda r) \sin (\lambda r)}{\operatorname{Sinh}^{2}(\lambda r)-\sin ^{2}(\lambda r)}\right]
$$

For quasi-static cracking to commence, we have the fracture criterion as

$$
\frac{M}{(R E I t)^{\frac{1}{2}}}=\frac{\operatorname{Sinh}^{2}(\lambda r)-\sin ^{2}(\lambda r)}{\operatorname{Sinh}^{2}(\lambda r)-2 \varepsilon \operatorname{Sinh}(\lambda r) \sin (\lambda r)+\sin ^{2}(\lambda r)}
$$

The theoretical values of $M /(R E I t)^{\frac{1}{2}}$ as a function of $\lambda r$ for varying $\varepsilon$ are shown in Fig. 8. It is obvious that only when $\lambda r>\pi$, will the fracture condition become $M^{2}=R E I t$. Freiman et al. [18] have used a grooved DCB testpiece with loading arrangements such that $\varepsilon=0$ and reported that at fracture, $M^{2}=R E I t$. However, they have not shown that

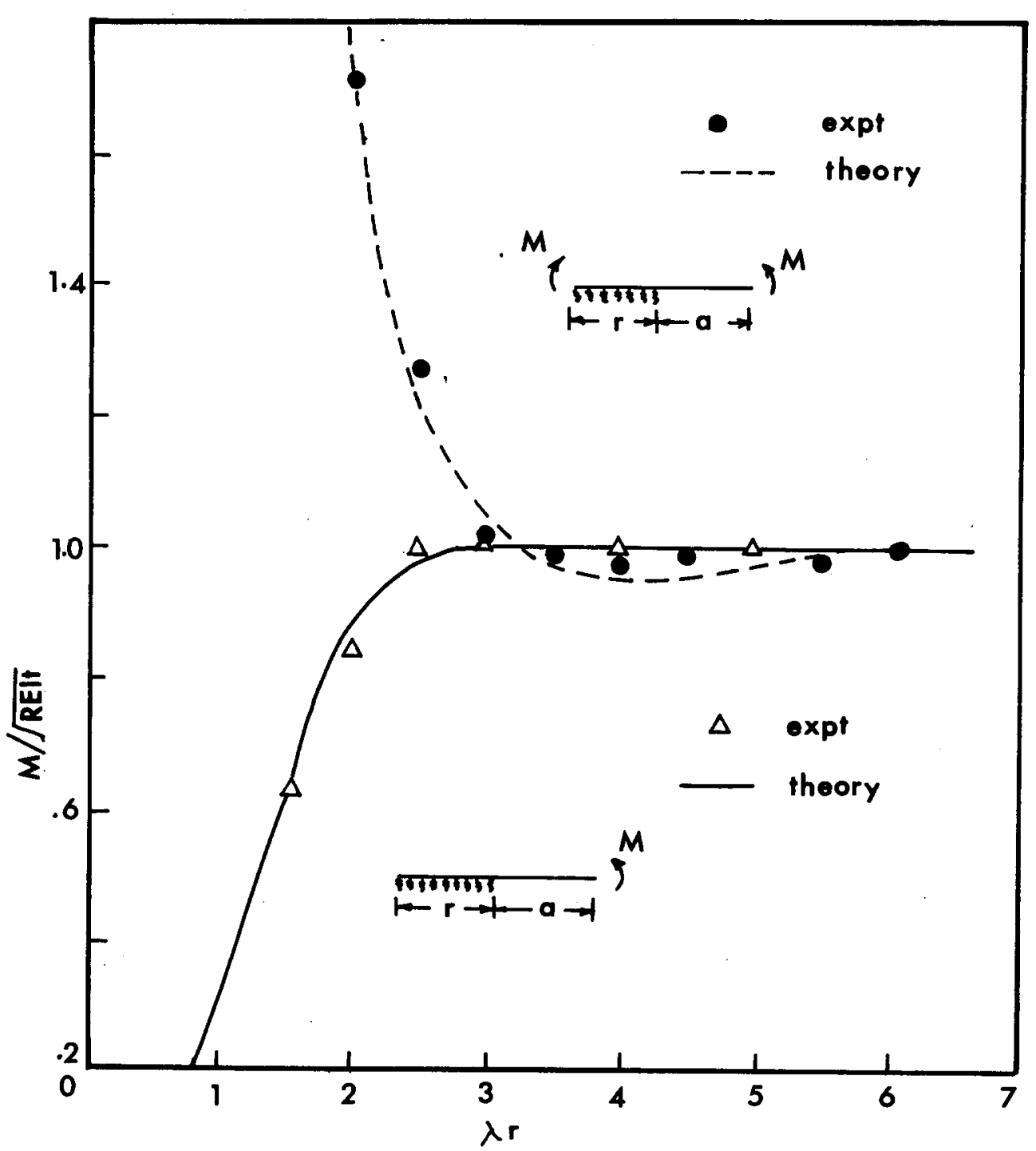

Figure 9. Comparison of experimental and theoretical bending moments to cause cracking for $\varepsilon=0$ and $\varepsilon=1.0$. 
$\lambda r>\pi$ is a necessary condition for this relation to hold. To prove this point and to verify the fracture criterion described in (18), experiments were performed using grooved beam-like testpieces made of Perspex and aluminum alloys ${ }^{\star}$, which were inserted into the special test rig developed in [2]. The $k_{e}$ values were determined experimentally with the testpieces inserted in the test rig, and $\lambda$ values calculated from $\left(k_{e} / 4 E I\right)^{\frac{1}{4}}$. Experimental results of $M /(R E I t)^{\frac{1}{2}}$ were obtained for $\varepsilon=1.0$ and $\varepsilon=0$ as a function of $\lambda r$. These results are plotted in Fig. 9 and they compare favorably with those predicted from (18). It is interesting to note that in these experiments performed in an Instron testing machine (where $\mathrm{d} u / u>0$ ), stable quasi-static cracking was achieved when $\varepsilon=1.0$ for all values of $\lambda r$. However, in contrast, cracking was unstable when $\varepsilon=0$ and $\lambda r$ small. These experimental results can be explained adequately in terms of the stability curves shown in Figs. 10(b) and 10(c).

The crack stability conditions may be worked out from (17) and (4) and (5). The analysis is tedious, and is not given here, but $n_{u}$ and $n_{p}$ are plotted as functions of $\lambda r$ for varying $\varepsilon$ in Figs. 10 (a)-(c).

For $\varepsilon=1.0$ in a displacement-controlled machine, Fig. 11 plots the variation of $n_{u}$ with $\lambda r$ for progressive crack extension in both an aluminum testpiece with $\lambda=2 \times 10^{-2}$ $\mathrm{mm}^{-1}, w=500 \mathrm{~mm}$ and in Perspex with $\lambda=4 \times 10^{-2} \mathrm{~mm}^{-1}$ and $w=125 \mathrm{~mm}$. It is

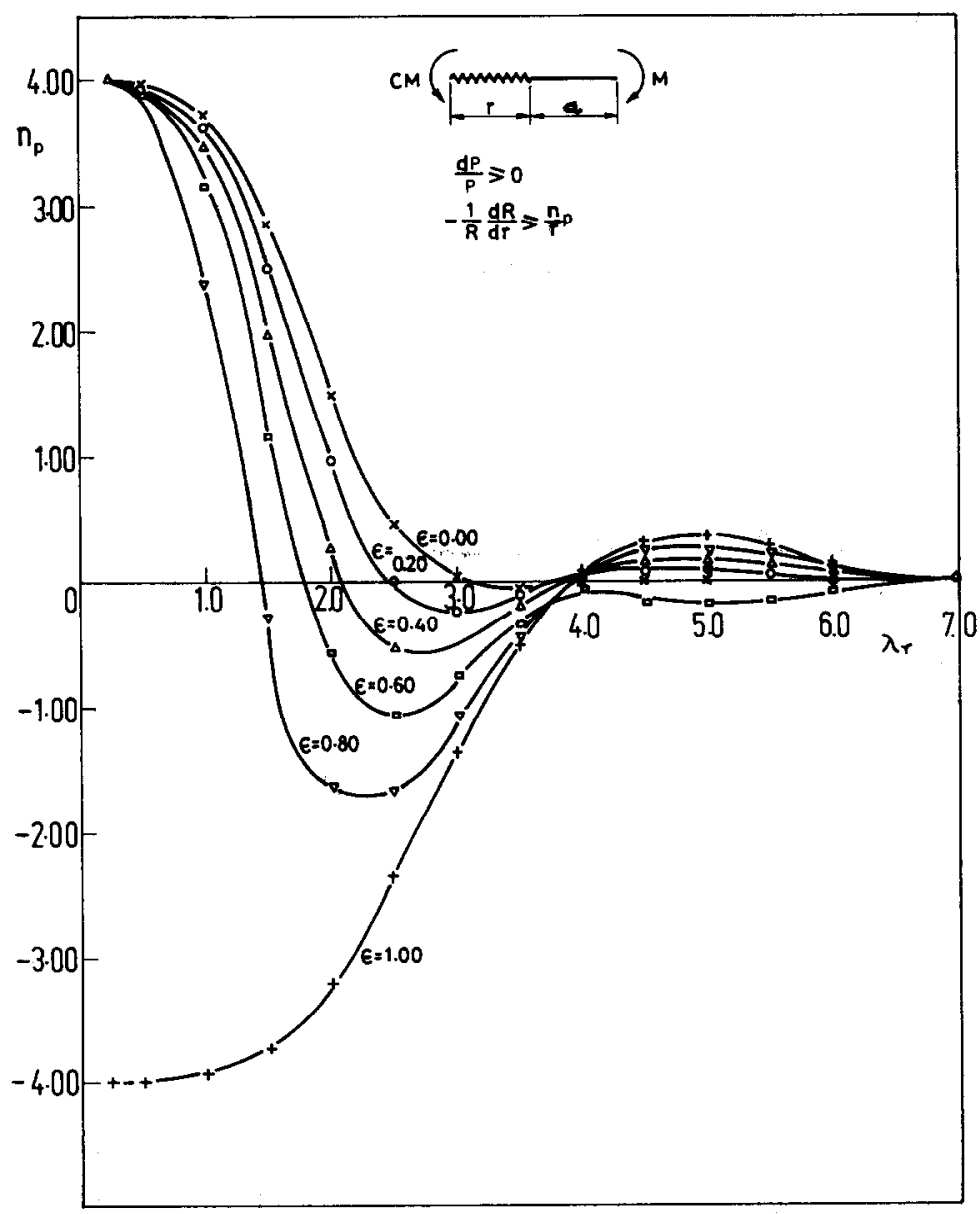

Figure 10(a). Variation of stability factor $n_{p}$ with $\lambda r$ for varying $\varepsilon$.

$\star$ The aluminum and Perspex grooved-specimens were identical to those used in previous investigations [2;19]. 

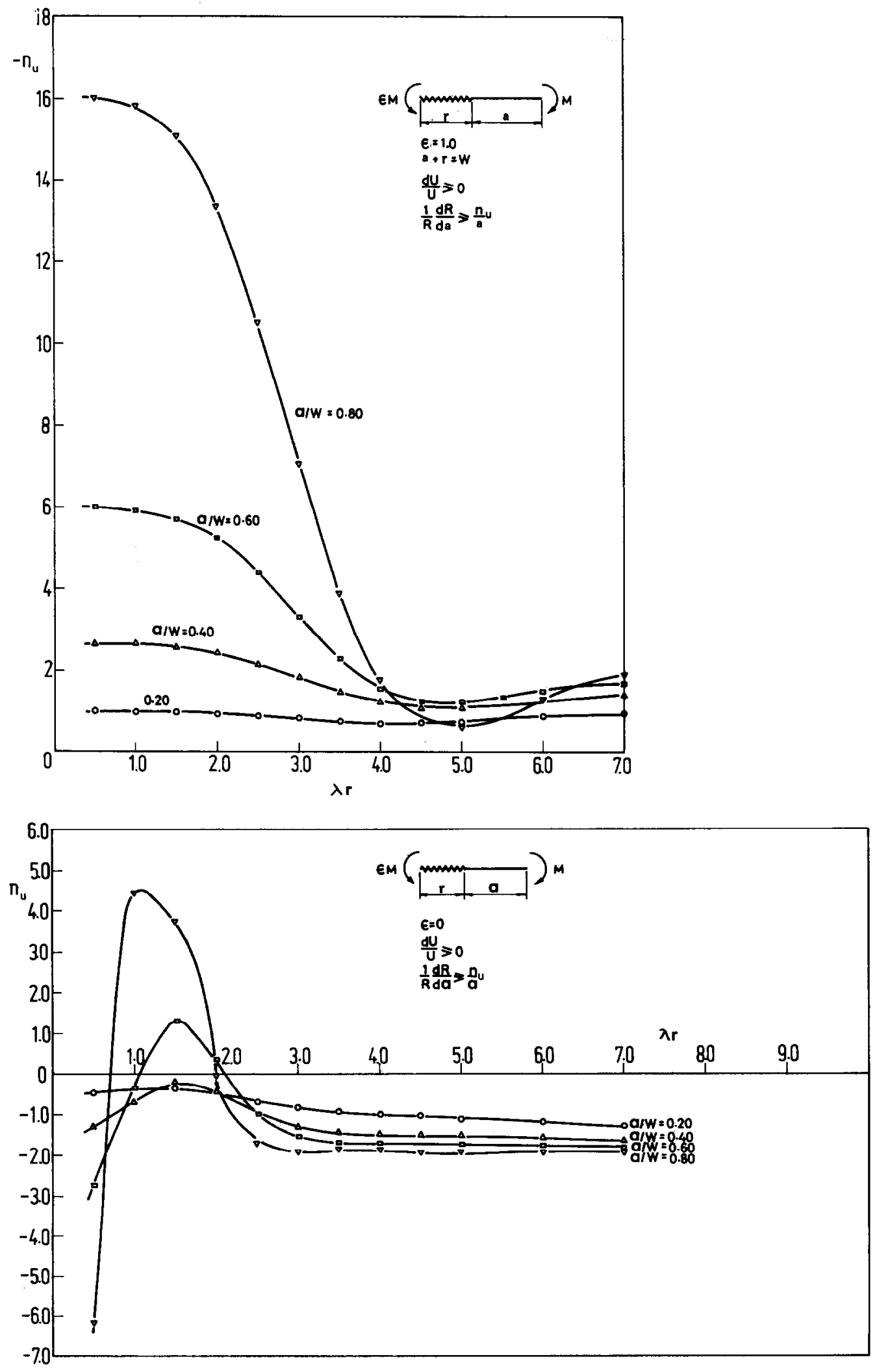

Figures $10(\mathrm{~b})$ and (c). Variation of $n_{u}$ with $\lambda r$ for $\varepsilon=1.0$ and $\varepsilon=0$. 


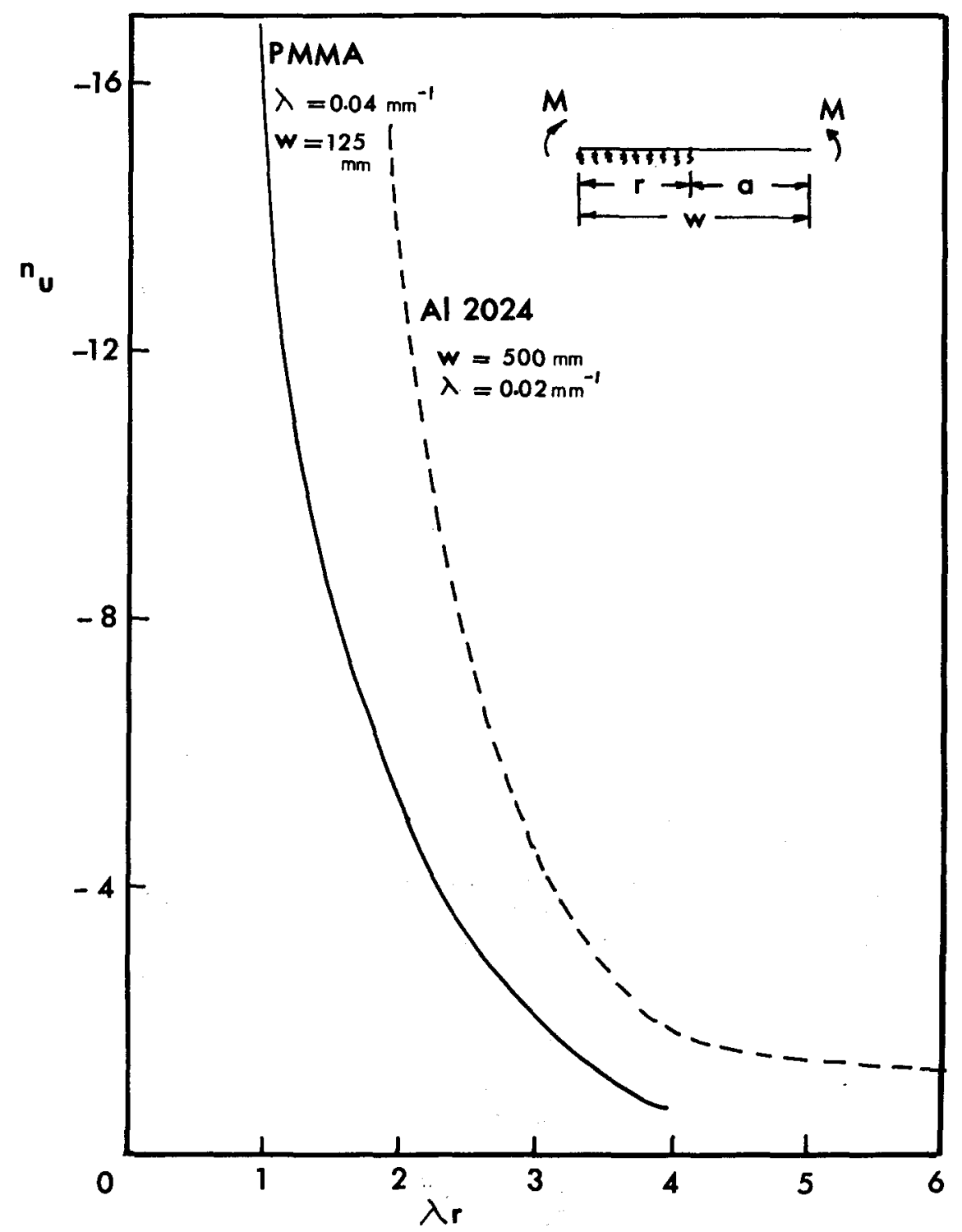

Figure 11. Variation of stability factor $n_{u}$ with $\lambda r$ during progressive cracking for perspex and aluminum specimens.

obvious that crack stability is greatly improved when compared with a similar case of an ungrooved testpiece which gives $n_{u}=-2[6]$. Other experimental results in support of these predictions have been reported in Gurney, Mai en Owen [2] and in Owen, Mai and Chow [19].

\section{Conclusions}

The present investigation shows that the beam-on-elastic foundation model is adequate for describing quasi-static fracture in grooved rectangular beam-like testpieces. The fracture criterion according to $M /(R E I t)^{\frac{1}{2}}=F(\lambda a, \lambda r)$ or equivalently, $R t=k_{e} v_{c}^{2}$, has been successfully verified by quasi-static crack propagation experiments. Moreover, crack stabilities in these grooved specimens have been investigated. 


\section{Acknowledgements}

This work was completed while the author was with the University of Hong Kong, Department of Mechanical Engineering. Thanks are due to Professor Charles Gurney for stimulating discussions of this paper and Mr. Robin C. Owen for experimental assistance. A research grant afforded by the Hong Kong University Research Grants Committee is gratefully acknowledged.

\section{REFERENCES}

[1] J. E. Srawley, in Fracture, Brighton Conference, (1969), Paper 12.

[2] C. Gurney, Y. W. Mai and R. C. Owen, Proc. Roy. Soc., London, A340 (1974) 213-231.

[3] M. F. Kanninen, Int. J. Fracture, 9 (1973) 83-92.

[4] M. F. Kanninen, Int. J. Fracture, 10 (1974) 415-430.

[5] M. Hetenyi, Beam on elastic foundation, University of Michigan Press, Ann Arbor, 1946.

[6] C. Gurney and J. Hunt, Proc. Roy. Soc., London, A299 (1967) 508-524.

[7] C. Gurney and Y. W. Mai, Engr. Fract. Mech., 4 (1972) 853-863.

[8] C. Gurney and K. M. Ngan, Proc. Roy. Soc., London, A325 (1971) 207-222.

[9] C. L. Chow and P. M. Lam, Journal of Eng. Materials \& Technology, 96 (1974) 41-48.

[10] D. P. Clausing, Int. J. Fract., 5 (1969) 211-228.

[11] J. I. Bluhm, Fracture Vol. 5, ed. H. Liebowitz, Academic Press, N.Y. (1969), Chapter 1.

[12] A. G. Atkins and R. M. Caddell, Engr. Fract. Mech., 6 (1974) 209.

[13] Y. W. Mai, A. G. Atkins and R. M. Caddell, Int. J. Fracture, 11 (1975) 939-953.

[14] Y. W. Mai, Int. J. Fract., 9 (1973) 349-351.

[15] Z. J. Bilek and S. J. Burns, J. Mech. Phys. Solids, 22 (1974) 85-95.

[16] F. A. Johnson and J. C. Radon, Engr. Fract. Mech., 4 (1972) 555-576.

[17] J. E. Srawley and W. F. Brown, Jr., In ASTM STP, 381 (1965) 133-198.

[18] S. W. Freiman, D. R. Mulville and P. W. Mast, Journal Materials Science, 8 (1973) 1527-1533.

[19] R. C. Owen, Y. W. Mai and C. L. Chow, Int. J. Fracture, 12 (1976) 3-17.

\section{RÉSUMÉ}

Dans ce mémoire, le critère de rupture pour des pièces rectangulaires entaillées en forme de poutres soumises à diverses conditions de mise en charge est analysé en recourant à un modèle d'une poutre simple posée sur une fondation élastique.

Des essais montrent que le modèle est adéquat pour décrire une rupture quasi statique dans le cas de géométries similaires à la géométrie étudiée. En outre, les conditions de stabilité de la fissure sont présentées pour les deux cas d'essais sur des machines à déplacement contrôlés et à charge contrôlée. 